\title{
Photodeposition of $\mathrm{Au}$ nanocatalysts onto $\mathrm{CuCrO}_{2}$ powders
}

\author{
Te-Wei CHIU, ${ }^{\dagger}$ Yu-Te LIN and Yi-An CHEN \\ Department of Materials and Mineral Resources Engineering, National Taipei University of Technology, \\ 1, Sec. 3, Zhongxiao E. Rd., Taipei, 106 Taiwan
}

\begin{abstract}
In this research, Au nanocatalysts were deposited on $\mathrm{CuCrO}_{2}$ powders using photodeposition to investigate the catalytic activity. Delafossite-type $\mathrm{CuCrO}_{2}$ porous powders were prepared using a glycine nitrate process. Au nanoparticles were photodeposited onto the $\mathrm{CuCrO}_{2}$ surface by irradiating light into $\mathrm{pH}$ adjusted $\mathrm{HAuCl}_{4}$ solution. The crystal structure, composition, and micromorphology of the derived $\mathrm{Au} / \mathrm{CuCrO} \mathrm{O}_{2}$ powders were characterized by $\mathrm{X}$-ray diffraction, $\mathrm{X}$-ray fluorescence, scanning electron microscopy, and transmission electron microscopy (TEM), respectively. TEM observation determined that the diameters of the $\mathrm{Au}$ nanoparticles photodeposited on $\mathrm{CuCrO}_{2}$ powder with $\mathrm{UV}$ irradiation at $\mathrm{pH}=10$ were approximately $4 \mathrm{~nm}$. The differential scanning calorimetric measurement indicated that $\mathrm{Au} / \mathrm{CuCrO}_{2}$ has a catalytic activity of carbon monoxide conversion.
\end{abstract}

(C2014 The Ceramic Society of Japan. All rights reserved.

Key-words : Delafossite, $\mathrm{CuCrO}_{2}$, Au nanoparticle, Catalyst, Photodeposition

[Received January 29, 2014; Accepted February 17, 2014]

\section{Introduction}

Haruta et al. discovered that gold nanoparticles deposited on metal-oxide supports show a strong catalytic activity of oxidizing carbon monoxide at temperatures as low as $-73^{\circ} \mathrm{C}$. ${ }^{1)}$ Since bulk gold is chemically inert and expresses poor catalytic activity, this novel finding opened up a new field of catalyst. Later studies revealed that the catalytic activity depended on the size of the gold clusters, support materials, and contact structures. Au nanoparticles express a higher catalytic activity at diameters of 2 to $4 \mathrm{~nm},{ }^{2)-4)}$ but they show a lower activity at diameters of less than $2 \mathrm{~nm}$, at which it tends to agglomerate. ${ }^{2)}$ To maximize the catalytic activity, it is essential to control the diameter of $\mathrm{Au}$ particles and provide a large surface area on the support.

Delafossite-type $\mathrm{CuBO}_{2}(\mathrm{~B}=\mathrm{Al}, \mathrm{Cr}, \mathrm{Y})$ materials have the potential for application in p-type transparent semiconductors. ${ }^{5)}$ It has also been reported that these materials show antibacterial and photocatalytic activities for removing heavy metals and generating hydrogen. ${ }^{6-8)} \mathrm{CuCrO}_{2}$ is a p-type semiconductor with a direct band gap of $3.1 \mathrm{eV} .^{9)}$ In our previous study, we prepared porous and homogeneous $\mathrm{CuCrO}_{2}$ powders using a glycine nitrate process. ${ }^{10)}$ The measured surface area of $\mathrm{CuCrO}_{2}$ powders was $30.92 \mathrm{~m}^{2} / \mathrm{g}$, which made them a potential candidate for the catalytic support. In this paper, we report our investigations of the preparation conditions of $\mathrm{Au}$ nanoparticles deposited on $\mathrm{CuCrO}_{2}$ powders by light irradiation and of the catalytic activity of the resulting material.

\section{Experimental procedure}

\subsection{Photodeposition of $\mathrm{Au}$ nanoparticles onto $\mathrm{CuCrO}_{2}$}

The $\mathrm{CuCrO}_{2}$ nanopowder was prepared according to reference. ${ }^{10)} \mathrm{HAuCl}_{4}$ solution was used as an $\mathrm{Au}$ precursor. First, $\mathrm{HAuCl}_{4}$ powder was dissolved in deionized water to make 100 $\mathrm{mL} 0.5 \mathrm{mM}$ solution. Then $0.5 \mathrm{~g}$ of $\mathrm{CuCrO}_{2}$ powder was added to

\footnotetext{
$\dagger$ Corresponding author: T.-W. Chiu; E-mail: tewei@ntut.edu.tw

* Preface for this article: Dol http://dx.doi.org/10.2109/jcersj2.122.P4-1
}

the solution with rapid stirring to disperse the $\mathrm{CuCrO}_{2}$ powders effectively into the $\mathrm{HAuCl}_{4}$ solution. The $\mathrm{pH}$ of the resulting dispersion was adjusted by adding a diluted ammonia solution. A $100 \mathrm{~W}$ tungsten lamp and a $250 \mathrm{~W}$ high-pressure mercury lamp $(365 \mathrm{~nm})$ were used as the sources of visible light and UV light for photodeposition, respectively. After being irradiated for 10 min, the slurry was filtered, washed, and dried overnight at $80^{\circ} \mathrm{C}$ in an oven. Finally, the $\mathrm{Au} / \mathrm{CuCrO}_{2}$ powder was annealed at $300^{\circ} \mathrm{C}$ for $4 \mathrm{~h}$ in atmosphere and subsequently stored in a desiccator in the dark.

\subsection{Characterization of samples}

The crystal structure was examined by X-ray diffraction spectroscopy (XRD) (Rigaku Dmax 2200 diffractometer), which involved $\mathrm{Cu} \mathrm{K} \alpha$ radiation $(\lambda=1.540 \AA)$. The chemical composition of as-prepared $\mathrm{Au} / \mathrm{CuCrO}_{2}$ powder was determined by X-ray fluorescence spectroscopy (XRF) (SII SEA6000VX). The microstructure of the $\mathrm{CuCrO}_{2}$ powder and $\mathrm{Au} / \mathrm{CuCrO}_{2}$ catalyst were investigated by scanning electron microscopy (SEM) (HITACHI S-4700) at $15 \mathrm{kV}$. The size of $\mathrm{Au}$ particle and the structure were analyzed by high-resolution transmission electron microscopy (TEM) (JEOL FE2100, $200 \mathrm{kV}$ ). The carbon monoxide oxidation activity was determined by differential scanning calorimetry (DSC).

\section{Results}

\subsection{XRD analysis}

Figure 1 shows $\mathrm{XRD}$ patterns of as-prepared $\mathrm{CuCrO}_{2}$ nanopowder and the $\mathrm{Au} / \mathrm{CuCrO}_{2}$ catalyst prepared by photodeposition. The as-prepared $\mathrm{CuCrO}_{2}$ powder exhibited typical $\mathrm{CuCrO}_{2}$ diffraction peaks, corresponding to the delafossite phase (JCPDS 39-0247). The broader peaks were mainly attributed to the nanosized $\mathrm{CuCrO}_{2}$. Clear gold patterns (JCPDS 04-7084) were obtained after photodeposition of $\mathrm{Au}$ particles onto $\mathrm{CuCrO}_{2}$ powder both by irradiation of visible light from a tungsten lamp at $\mathrm{pH}=10$ and by UV light from a mercury lamp at various $\mathrm{pH}$ values. The XRD spectrum indicates that the gold particles were successfully deposited onto the $\mathrm{CuCrO}_{2}$ support without 


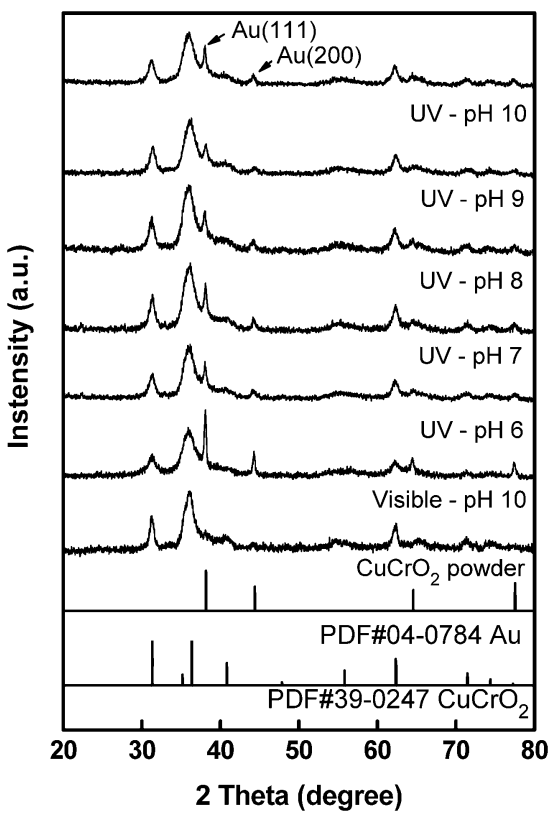

Fig. 1. $\mathrm{XRD}$ patterns of as-prepared $\mathrm{CuCrO}_{2}$ powder and $\mathrm{Au} / \mathrm{CuCrO}_{2}$ catalyst.

Table 1. XRF analysis results of $\mathrm{Au} / \mathrm{CuCrO}_{2}$ catalyst

\begin{tabular}{lccc}
\hline Sample & $\mathrm{Cu}$ & $\mathrm{Cr}$ & $\mathrm{Au}$ \\
\hline Visible-pH 10 & $45.9 \%$ & $34.3 \%$ & $2.0 \%$ \\
UV-pH 6 & $46.1 \%$ & $34.7 \%$ & $1.9 \%$ \\
UV-pH 7 & $46.1 \%$ & $34.5 \%$ & $2.3 \%$ \\
UV-pH 8 & $45.8 \%$ & $34.6 \%$ & $2.3 \%$ \\
UV-pH 9 & $46.1 \%$ & $34.4 \%$ & $2.4 \%$ \\
UV-pH 10 & $46.2 \%$ & $34.4 \%$ & $2.0 \%$ \\
\hline
\end{tabular}

any chemical interaction. XRD peaks attributed to Au particles prepared by visible light irradiation were higher and narrower than those prepared by UV light irradiation. The photodeposition was carried out at room temperature, and no chemical reaction between $\mathrm{Au}$ and $\mathrm{CuCrO}_{2}$ occurred, as indicated in the XRD analysis in Fig. 1.

\subsection{XRF measurement}

Table 1 lists a summary of the XRF results for photodeposited $\mathrm{Au} / \mathrm{CuCrO}_{2}$. In samples obtained by visible light irradiation and those obtained by UV light irradiation, the compositions of $\mathrm{Au} /$ $\mathrm{CuCrO}_{2}$ were similar. The $\mathrm{Au}$ content in the $\mathrm{Au} / \mathrm{CuCrO}{ }_{2}$ system was about $2 \%$. The Au content, which is related to the particle size and coverage over support, is a critical factor for evaluating the catalytic activity of the $\mathrm{Au} /$ support system.

\subsection{SEM microstructure}

Figure 2 shows the microstructure of the as-prepared $\mathrm{CuCrO}_{2}$ nanopowder at $15 \mathrm{kV}$. It was composed of randomly-arranged thin porous membranes. The pores varied in size from nanometers to micrometers, providing a high surface area. Figure 3 presents an SEM image of $\mathrm{Au}$ photodeposited by visible light irradiation at $\mathrm{pH}=10$. Au particles were dispersed in the $\mathrm{CuCrO}_{2}$ porous structure. However, the Au particles were relatively large and consistent with the narrow and sharp XRD pattern in Fig. 1. These results did not achieve our goal of depositing nanosized $\mathrm{Au}$ particles on the $\mathrm{CuCrO}_{2}$ surface. Because the direct energy gap of

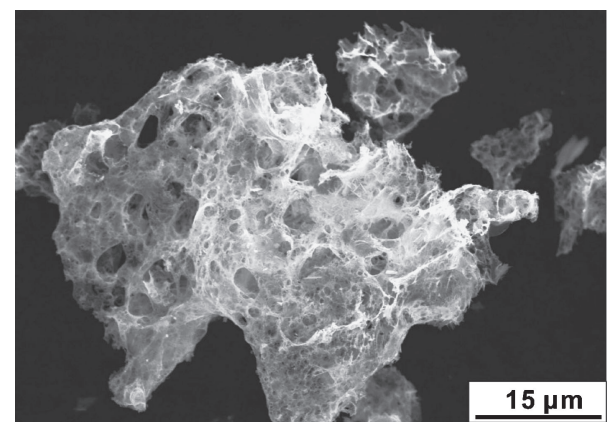

Fig. 2. SEM image of as-prepared $\mathrm{CuCrO}_{2}$ powder.

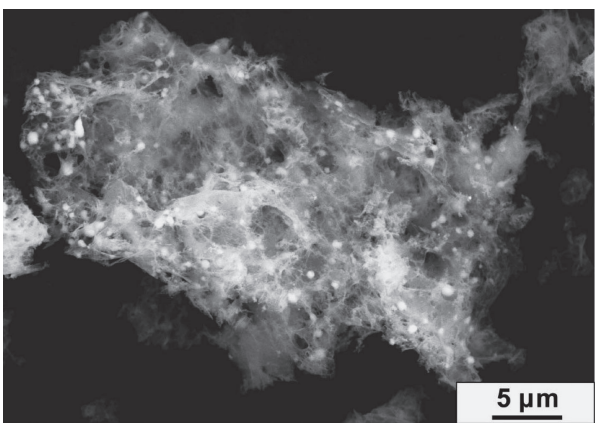

Fig. 3. SEM image of $\mathrm{Au} / \mathrm{CuCrO}_{2}$ catalyst prepared by visible light irradiation at $\mathrm{pH}=10$.

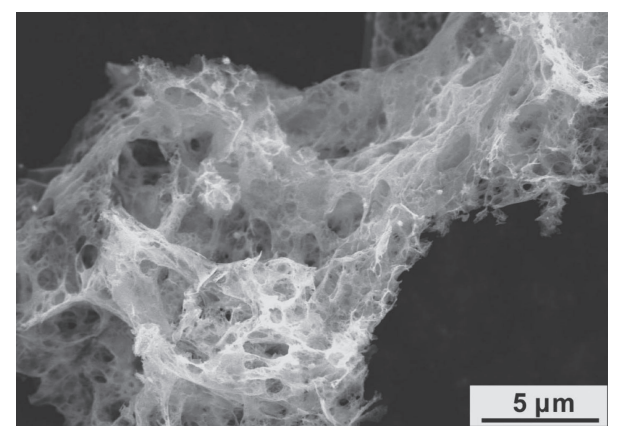

Fig. 4. SEM image of $\mathrm{Au} / \mathrm{CuCrO}_{2}$ catalyst prepared by UV light irradiation at $\mathrm{pH}=10$.

$\mathrm{CuCrO}_{2}$ is higher than $3.1 \mathrm{eV}$, visible light cannot activate it. However, the defect spots in $\mathrm{CuCrO}_{2}$ could be activated by visible light, and the $\mathrm{Au}$ was photodeposited on these sites in agglomerated clusters.

Figure 4 presents an SEM image of Au photodeposited by UV light irradiation at $\mathrm{pH}=10$. Although several large Au particles can be observed, the basic microstructure was the same as that of the as-prepared $\mathrm{CuCrO}_{2}$ (Fig. 2).

\subsection{TEM observation}

We used TEM to determine if the small gold clusters were present on the $\mathrm{CuCrO}_{2}$-support. Figure 5 presents a TEM image of $\mathrm{Au}$ photodeposited by visible light irradiation at $\mathrm{pH}=10$. Large Au particles of about $100 \mathrm{~nm}$ can be clearly observed, but no nano-sized $\mathrm{Au}$ particles are in evidence. Figure 6(a) shows a TEM image of Au photodeposited by UV light irradiation at $\mathrm{pH}=10$. Figures $6(\mathrm{~b})-6(\mathrm{~d})$ are enlargements of the square areas in Fig. 6(a)-6(c), respectively. The gold clusters (tiny darker spots) were evenly distributed on the $\mathrm{CuCrO}_{2}$-support [Fig. 6(c)]. 


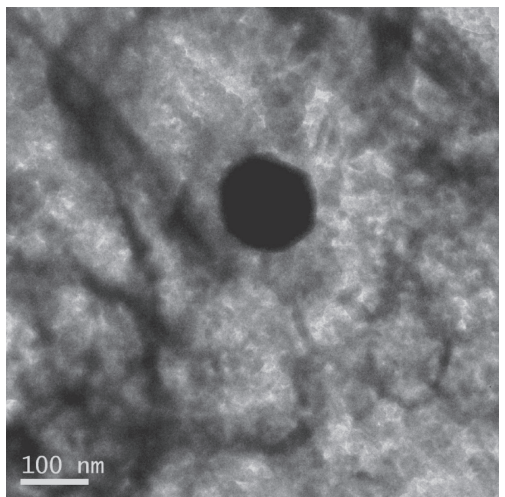

Fig. 5. TEM image of $\mathrm{Au} / \mathrm{CuCrO}_{2}$ catalyst prepared by visible light irradiation at $\mathrm{pH}=10$

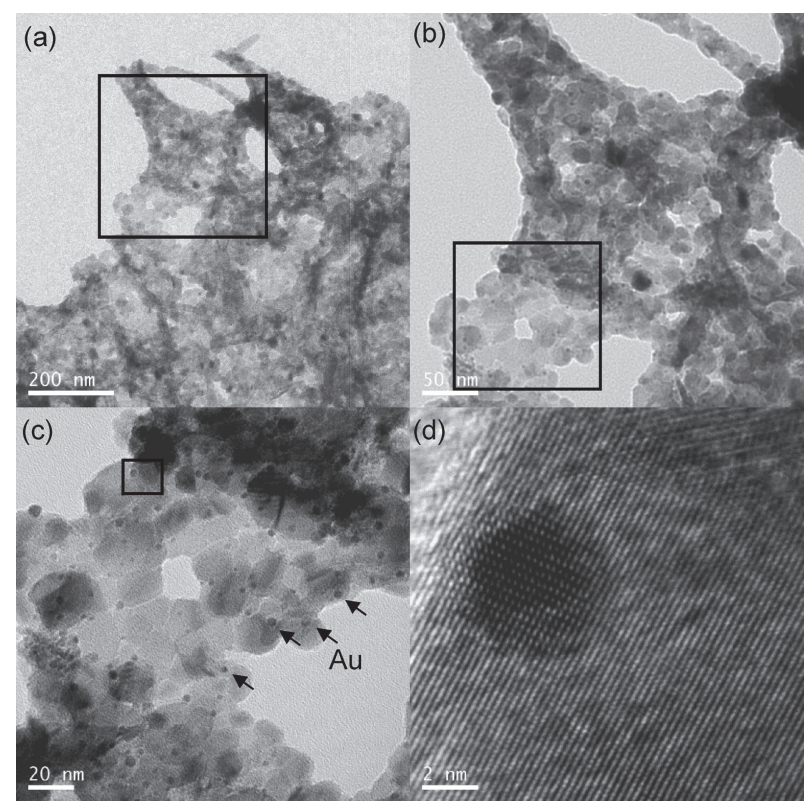

Fig. 6. TEM image of $\mathrm{Au} / \mathrm{CuCrO}_{2}$ catalyst prepared by UV light irradiation at $\mathrm{pH}=10$.

The average diameter of the gold clusters was approximately $4.0 \mathrm{~nm}$, which is within the range required for optimal catalytic oxidation activity. The high density of the gold clusters on the $\mathrm{CuCrO}_{2}$ support provided the $\mathrm{Au} / \mathrm{CuCrO}{ }_{2}$ catalyst with a large three-phase interface area, which is necessary to yield high levels of catalytic activity.

\subsection{Catalytic activity}

We used DSC to measure the catalytic activity of $\mathrm{Au} / \mathrm{CuCrO}{ }_{2}$ toward carbon monoxide. Exothermic peaks in the DSC plot would confirm a reaction between the $\mathrm{Au} / \mathrm{CuCrO}_{2}$ catalyst and carbon monoxide. Figure 7 shows a DSC plot of the $\mathrm{Au} /$ $\mathrm{CuCrO}_{2}$ catalyst prepared by visible light irradiation at $\mathrm{pH}=10$ and UV irradiation at various $\mathrm{pH}$ values. All samples showed exothermic peaks after carbon monoxide was introduced into the DSC chamber. $\mathrm{Au} / \mathrm{CuCrO}_{2}$ catalyst prepared by visible light irradiation at $\mathrm{pH}=10 \mathrm{had}$ an almost flat line, indicating that the catalytic activity was very low. The most likely explanation for this level of activity is that the particle size was too large, as shown in Fig. 3. The observed heat flows are listed in Table 2. All of the $\mathrm{Au} / \mathrm{CuCrO}_{2}$ catalyst prepared by UV irradiation

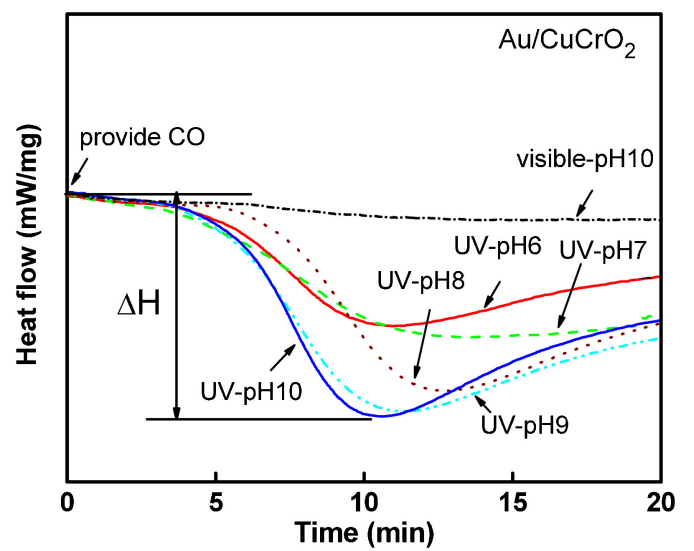

Fig. 7. DSC measurement of catalytic activity of $\mathrm{Au} / \mathrm{CuCrO}_{2}$.

Table 2. Heat flow of $\mathrm{Au} / \mathrm{CuCrO}_{2}$ catalysts reacting with carbon monoxide

\begin{tabular}{cc}
\hline Sample & Heat flow $(\mathrm{mW} / \mathrm{mg})$ \\
\hline Visible-pH 10 & 0.02 \\
UV-pH 6 & 0.585 \\
UV-pH 7 & 0.642 \\
UV-pH 8 & 0.883 \\
UV-pH 9 & 0.981 \\
UV-pH 10 & 1.008 \\
\hline
\end{tabular}

showed decreases in heat flow, indicating that the $\mathrm{Au} / \mathrm{CuCrO}_{2}$ catalyst reacted with the carbon monoxide. In this study, the highest catalytic activity was exhibited by the $\mathrm{Au} / \mathrm{CuCrO}_{2}$ prepared by UV irradiation at $\mathrm{pH}=10$.

\section{Discussion}

The nano-deposition of $\mathrm{Au}$ particles onto $\mathrm{CuCrO}_{2}$ nanopowder was accomplished with the photodeposition method in $\mathrm{HAuCl}_{4}$ solution. Since $\mathrm{CuCrO}_{2}$ is a p-type semiconductor with a direct bandgap of $3.1 \mathrm{eV}$, it absorbed UV light during the photodeposition process to generate electron-hole pairs. The $\mathrm{Au}^{3+}$ ions in the $\mathrm{HAuCl}_{4}$ solution caught these UV-pumped electrons and precipitated onto the $\mathrm{CuCrO}_{2}$ surface as $\mathrm{Au}$ metal clusters. The atomic ratio of $\mathrm{Au}: \mathrm{CuCrO}_{2}$ was $0.02: 1$, according to XRF measurement. These deposited $\mathrm{Au}$ nanoparticles were approximately $4 \mathrm{~nm}$ in diameter and were uniformly deposited onto the $\mathrm{CuCrO}_{2}$ surface. If the surface area density of the $\mathrm{CuCrO}_{2}$ powder is assumed to be $30.92 \mathrm{~m}^{2} / \mathrm{g}$ [5], and the diameter of the Au nanoparticles was $4 \mathrm{~nm}$, it follows that the Au particle density over the surface area was $0.13 / \mathrm{nm}^{2}$, according to the $2 \% \mathrm{Au}$ atomic ratio in the $\mathrm{CuCrO}_{2}$ support. However, the density of $\mathrm{Au}$ nanoparticles observed in TEM images was $0.01 / \mathrm{nm}^{2}$, which is one order of magnitude smaller. This result indicates that the process parameters, such as the dispersion degree of solid nanopowder support in the solution, solution concentration, temperature, UV irradiation intensity, and stir speed, might need to be optimized to increase the $\mathrm{Au}$ nanoparticle density over the surface area to maximize catalytic activity.

The preliminary results on catalytic activity reveal that the $\mathrm{Au} /$ $\mathrm{CuCrO}_{2}$ system has a oxidation activity against carbon monoxide. The DSC measurement demonstrated an exothermic energy change of $1.008 \mathrm{~mW} / \mathrm{mg}$ upon the introduction of $\mathrm{CO}$ gas into the chamber. The performance of the $\mathrm{Au}$ nanocatalyst is determined by the particle size, contact structure, and support materials. ${ }^{11)}$ This is the first study to employ a multicomponent p-type 
oxide as the supporting material for an Au nanocatalyst. It is also reported that copper-containing compounds, such as superconducting and pyrochlore, ${ }^{12), 13)}$ have certain catalytic activity. We can thus expect a synergistic effect of Au nanoparticles and copper-containing support in certain catalytic chemistry. We believe that the variety of the delafossite group and its tunable band gap will allow expansion of the applications of such materials in the area of catalysis.

\section{Conclusion}

Gold catalysts supported on $\mathrm{CuCrO}_{2}$ powder were prepared by photodeposition method. Visible light and UV light were used as light sources for photodeposition. Visible light irradiation caused large Au clusters $(>50 \mathrm{~nm})$ to be deposited on $\mathrm{CuCrO}_{2}$, and $\mathrm{UV}$ radiation caused nanosized $\mathrm{Au}$ particles $(\sim 4 \mathrm{~nm})$ to be deposited on $\mathrm{CuCrO}_{2}$ support. The catalytic activity of $\mathrm{Au} / \mathrm{CuCrO}_{2}$ reacting with carbon monoxide was measured by DSC and thus confirmed. The highest catalytic activity, $1.008 \mathrm{~mW} / \mathrm{g}$, was exhibited by the $\mathrm{Au} / \mathrm{CuCrO}_{2}$ prepared by $\mathrm{UV}$ irradiation at $\mathrm{pH}=10$.

Acknowledgement This work was financially supported by the National Science Council of Taiwan under Contract No. NSC982218-E-027-004 and Much Fortune Tech Co Ltd.

\section{References}

1) M. Haruta, T. Kobayashi, H. Sano and N. Yamada, Chem. Lett., 2, 405-408 (1987).

2) M. Okumura, S. Nakamura, S. Tsubota, T. Nakamura, M. Azuma and M. Haruta, Catal. Lett., 51, 53-58 (1998).

3) T. Hayashi, K. Tanaka and M. Haruta, J. Catal., 178, 566-575 (1998).

4) M. Haruta, N. Yamada, T. Kobayashi and S. Iijima, J. Catal., 115, 301-309 (1989).

5) H. Kawazoe, M. Yasukawa, H. Hyodo, M. Kurita, H. Yanagi and H. Hosono, Nature, 389, 939-942 (1997).

6) T.-W. Chiu, Y.-C. Yang, A.-C. Yeh, Y.-P. Wang and Y.-W. Feng, Vacuum, 87, 174-177 (2013).

7) W. Ketir, A. Bouguelia and M. Trari, Water Air Soil Pollut., 199, 115-122 (2009)

8) S. Saadi, A. Bouguelia and M. Trari, Sol. Energy, 80, 272-280 (2006).

9) T.-W. Chiu, S.-W. Tsai, Y.-P. Wang and K.-H. Hsu, Ceram. Int., 38, S673-S676 (2012).

10) T.-W. Chiu, B.-S. Yu, Y.-R. Wang, K.-T. Chen and Y.-T. Lin, J. Alloys Compd., 509, 2933-2935 (2011).

11) H. Masatake, Chem. Rec., 3, 75-87 (2003).

12) L. B. Khlil, W. E. Mourad and M. W. Rophael, J. Chem. Technol. Biotechnol., 61, 117-121 (1994).

13) Y. Xuan, C. H. He, R. Wang, R. Liu and Y. Q. Jia, Catal. Lett., 46, 119-121 (1997). 